\title{
Behaviour, brain and body growth of guinea-pigs after prenatal growth restriction
}

\author{
By ELIZABETH A. BYRNE, J. L. SMART, J. DOBBING \\ AND JEAN SANDS \\ Department of Child Health, University of Manchester, Medical School, Stopford Building, \\ Oxford Road, Manchester Mi3 $9 P T$
}

\author{
(Received 20 January 1978 - Accepted 9 March 1978)
}

\begin{abstract}
1. Guinea-pigs were growth-retarded in early life by feeding their mothers a restricted quantity of food during the second half of pregnancy. After birth, all animals were fed ad lib. Body-weights were recorded weekly and behavioural tests were made on adult males. The animals were then killed and their brains dissected into forebrain, cerebellum and brain stem. These regions were weighed and DNA-phorphorus content measured.

2. At I4 weeks each male was paired with another male for 10 min on four consecutive days and their social behaviour scored. Tests I and 2 were on like-treatment pairs and tests 3 and 4 on unlike-treatment pairs. At 25 weeks the same animals were subjected to six graded series of brief, unavoidable shocks and their responses recorded. After $3 \mathrm{~d}$, thresholds of aversion to electric shock were measured by recording the period of time spent on the 'safe' side of a rectangular box at five shock levels.

3. Undernourished guinea-pigs were significantly lighter than controls at birth but not at adulthood. Regional brain weights and DNA-P content of previously-undernourished guinea-pigs were significantly lower than those of controls, with the greatest deficit in brain stem.

4. Pairs of previously-undernourished guinea-pigs began to interact more quickly and threatened and nosed each other more often than pairs of controls. In mixed pairs previously-undernourished animals chased controls more than their control partners chased them. There were no differences between groups in responsiveness to unavoidable shock or in aversion thresholds.
\end{abstract}

The literature on the behavioural effects of early undernutrition is dominated by studies on rats, with relatively few investigations of other species (Smart, 1977). Clearly the more species investigated, the more confident may be any attempts to extrapolate findings from one species to another, including man. The guinea-pig, which has never been studied in this context, is particularly interesting because its brain growth-spurt is almost entirely prenatal unlike any other commonly-used laboratory animal (Dobbing \& Sands, 1970). Hence we might predict that, unlike man and the rat which have predominantly postnatal brain growth-spurts, the guinea-pig ought to be most vulnerable to prenatal growth restriction.

In the present experiment guinea-pigs were examined in adulthood for lasting effects of prenatal undernutrition on behaviour and brain growth. Foetal guinea-pigs were growth-retarded by underfeeding their mothers during the second half of pregnancy, then nutritionally rehabilitated from birth. The aspects of behaviour selected for study were two of those which are reliably found to be affected by early life undernutrition in the rat: social behaviour (Whatson, Smart \& Dobbing, 1974; Tikal, Benešová \& Franková, 1976) and responsiveness to electric shock (Smart, Whatson \& Dobbing, 1975; Lynch, 1976).

\section{METHODS}

\section{Rearing conditions and nutritional treatments}

The guinea-pigs used were albinos of the Dunkin Hartley strain. They were kept at a temperature of $20 \pm I^{\circ}$ and their daily light cycle was $\mathrm{I} 2 \mathrm{~h}$ red light-I $2 \mathrm{~h}$ white light with the change to white light at 08.00 hours. For mating, virgin females were housed five to ten 
per cage with one male, in wire-mesh pens measuring $750 \times 600 \times 300 \mathrm{~mm}$ high. The day of mating (day o of pregnancy) was determined by vaginal membrane absence (Elvidge, 1972). From day 35 of pregnancy until parturition all females were caged singly in wire-mesh cages measuring $300 \times 400 \times 200 \mathrm{~mm}$ high.

All pregnant and lactating females received a solution of ascorbic acid (approximately $1 \mathrm{~g} / \mathrm{l}$ ) ad lib. instead of water. The control animals were fed on a pelleted commercial diet, SG I, ad lib. (Short \& Gammage, 1959). Their daily consumption was recorded and undernourished animals were given $50 \%$ of this daily from day 35 of pregnancy until parturition. The absolute daily amount increased with the normal increase in the consumption of the controls during the second half of pregnancy. All animals were given approximately $50 \mathrm{~g}$ cabbage three times weekly. Hay was fed daily until day 35, but not thereafter. Bodyweights of control and undernourished females were recorded on day o of pregnancy and weekly from day 35 until parturition.

Inspection for litters occurred daily between 09.00 and 10.00 hours. On the day of birth (postnatal day o) young were weighed and sexed. All animals were fed $a d$ lib. from the day of birth and hay was given three times weekly. Young animals were weighed weekly from day 0 . They were weaned on day $2 \mathrm{I}$ and housed in litter-mate groups until day 35 . They were then housed in single sex litter-mate groups if there was more than one animal of each sex in the litter, or, if not, in single sex groups of two to four animals, as near as possible to each other in age until testing.

There were nine control and fourteen undernourished females at the beginning of the study. Due to the loss of litters from maternal deaths, abortions or still births and the loss of individual young pre- and postnatally the number of male guinea-pigs available for testing at adulthood was twelve control (C) males from five litters and eleven previouslyundernourished (PU) males from five litters. Only males were tested in the experiments described.

\section{Testing procedures}

I. Social behaviour. The animals were caged singly at approximately i 4 weeks. Habituation began the next day. Testing began $7 \mathrm{~d}$ later. The testing chamber was a wire-mesh cage measuring $450 \times 450 \times 400 \mathrm{~mm}$ high, with a grid floor divided into nine squares of equal area. Testing was carried out in the colony room to minimize freezing behaviour and observations were made indirectly with the aid of a closed-circuit television system.

Each animal was placed alone in the observation box for 10 min on each of $6 \mathrm{~d}$ before testing. During these habituation sessions an observer used manual counters for scoring the number of squares entered, frequency of rearing on the hind-legs against the sides of the box, latency to move on being placed in the box and the total duration of inactivity. Beginning the day after the last of these sessions each animal was observed in the box with another animal during Io min sessions on four consecutive days. In tests I and 2 strange males of unlike-treatment groups were put together and in tests 3 and 4 strange males of like-treatment groups paired. No two guinea-pigs met more than once, and litter-mates or previous cage-mates were never paired. In both habituation and test sessions the order of testing was varied randomly from day to day. Faecal boluses were removed from the observation box after each test session, but it was not otherwise cleaned between sessions.

The behaviours recorded were defined as follows: nose, the orientation of the head of one guinea-pig towards another in close proximity to it; allogroom, the nibbling or licking of the fur of another guinea-pig; threat, the raising of the head with the mouth half open, in which the head may be jabbed towards the other animal which may in turn 'evade'; evade, the sharp withdrawal of the head or fore-part of the body; chase, one animal swiftly 
follows another which 'flees'; flee, an animal moves quickly away from the one chasing it; bite; crouch, the animal freezes, usually in a corner with its rear towards the other animal; sniff, the orientation of the head of one guinea-pig towards the ano-genital region of another; mount, one animal stands behind and against the back of another, clasping the flanks with its forepaws; latency to interaction, period of time from the beginning of a test to the occurrence of the first interaction; initiator, the guinea-pig which makes the first approach in a test; ambulation, the number of squares entered by an animal.

2. Shock thresholds. The animals used in the social behaviour study continued to be housed singly until further testing began at approximately 25 weeks of age.

Expt I. They were tested in a rectangular aluminium box, $240 \times 210 \times 90 \mathrm{~mm}$ high, the front wall of which was transparent Perspex. The floor was a grid of $4 \mathrm{~mm}$ diameter stainless-steel bars, spaced $14 \mathrm{~mm}$ between centres, through which electric shocks could be delivered, using a constant-power shock-source with scrambler which could deliver electric shocks of variable voltage from a source resistance of $150000 \Omega$.

The procedure was similar to that of Smart et al. (I975). After 2 min habituation to the test box, six series of unavoidable electric shocks were delivered to the animal's feet. Each series consisted of nine stimulations at the following voltages: 0, 60, 70, 80, 90, 100, 110 , I 20, I $30 \mathrm{~V}$. The shocks were presented in random order, the order differing for each series. Shocks were of I s duration and were presented at $30 \mathrm{~s}$ intervals. The inter-series interval was $2 \mathrm{~min}$. The shock source and test box were in separate rooms. A light cue, visible only to the observer, alerted her to shock onset.

Guinea-pigs were scored at each shock presentation for the following behaviours: flinch, any movement which did not involve movement of the feet; jump, the removal of one or more feet from the grid but without gross body movements; move, gross body movement; vocalize, usually a squeal; quiver, a trembling of the body which usually lasted for the entire inter-shock interval.

Expt 2. There was an interval of $3 \mathrm{~d}$ between the end of Expt $\mathrm{I}$ and the measurement of aversion thresholds. The apparatus was a rectangular aluminium 'shuttle' box, with the centre partition removed, $500 \times 220 \times 220 \mathrm{~mm}$ high with a grid floor of $8 \mathrm{~mm}$ diameter stainless-steel bars spaced $23 \mathrm{~mm}$ between centres. This was connected to the shock-source already described. The method was a modification of that described by Campbell (I967).

Each guinea-pig was placed in the box with the shock switched off for 5 min. Then a shock of predetermined level was applied to the side on which the animal was located. Responses as described in Expt I were recorded. When the animal crossed to the other side of the box the shock was switched off and remained off as long as the animal stayed on that side. If it returned to the first side, shock of the same level was turned on for as long as it remained there. After 10 min the shock level was changed to another predetermined level, and applied to the side of the box on which the animal was located. Thus, for each shock level, preference for the 'no shock' side of the box was tested and the period of time spent on this side recorded. The order of presentation of the six shock levels was randomized and each level presented three times. The order of presentation was the same for all guinea-pigs: $90,180,210,150,60,120,150,180,90,210,60,120,210,150,180,90,120$ and $60 \mathrm{~V}$.

\section{Brain dissection and chemical analysis}

The guinea-pigs were killed at approximately $200 \mathrm{~d}$ of age. The brains were removed immediately after death. They were separated from the spinal cord at the foramen magnum and divided into forebrain, brain stem and cerebellum. Forebrain was separated from brain stem immediately anterior to the corpora quadrigemina. Each region was weighed and homogenized and then stored at -15 to $-20^{\circ}$ for subsequent analysis of DNA- 
Table I. Body-weights of control $(C)$ and previously-undernourished $(P U)$ guinea-pigs* at four ages

(Mean values with their standard errors; no. of animals in parentheses)

\begin{tabular}{|c|c|c|c|c|c|}
\hline \multirow[b]{3}{*}{ Age (d) } & \multicolumn{4}{|c|}{$\mathrm{W}(\mathrm{g})$} & \multirow{3}{*}{$\begin{array}{l}\text { Statistical significance } \\
\text { of differences between } \\
\text { treatment groups }\end{array}$} \\
\hline & \multicolumn{2}{|c|}{$C(\mathrm{I} 2)$} & \multicolumn{2}{|c|}{ PU (II) } & \\
\hline & Mean & SE & Mean & SE & \\
\hline 0 & $97 \cdot 00$ & 3.54 & 65.90 & $2 \cdot 98$ & $P<0.01$ \\
\hline 42 & $472 \cdot 00$ & 10.34 & $398 \cdot 36$ & 11.75 & $P<0.0 \mathrm{I}$ \\
\hline 98 & 676.25 & $21 \cdot 38$ & $666 \cdot 27$ & 18.78 & NS \\
\hline 200 & $801 \cdot 66$ & $21 \cdot 23$ & 886.63 & 26.85 & NS \\
\hline
\end{tabular}

phosphorus (as an index of cell number) by the method of Zamenhof, Bursztyn, Rich \& Zamenhof (1964).

Statistics

Frequency distributions of all results were constructed before statistical analysis. For instances in which distributions were judged by eye to deviate from Gaussian, median values were used as measures of central tendency and analysis was by the Mann-Whitney $U$ test (two-tailed). Otherwise the mean values have been presented and analysis was by parametric statistics: $t$ test for independent samples, analysis of variance with repeated measures and analysis of covariance.

\section{RESULTS}

\section{Body-weight}

At birth and $42 \mathrm{~d}$ the PU guinea-pigs were significantly lighter than $\mathrm{C}$ guinea-pigs. However, from the time at which testing began at $98 \mathrm{~d}$ until the animals were killed at $200 \mathrm{~d}$, there was no significant difference in body-weight between the two groups (Table I). There was no significant difference between $\mathrm{C}$ and PU guinea-pigs in litter size, although the range was quite large (two to five in both groups). Results were analysed using an analysis of covariance with litter size as covariant to control for the effect of this on body-weight (Winer, I97I). At no age was there a significant difference between the nutritional groups in slopes of the litter size $v$. body-weight regression lines.

\section{Brain weight}

At $200 \mathrm{~d}$ there was a significant difference in whole brain weight between $\mathrm{C}$ and PU guineapigs. The differences in regional brain weights were also significant with the greatest percentage deficit in brain stem weight and the smallest in cerebral weight (Table 2). These differences were paralleled by similar deficits in DNA-P content. There was no significant difference between groups in DNA-P concentration.

\section{Social behaviour}

There were no differences between $\mathrm{C}$ and PU guinea-pigs in any of the behaviours recorded during the habituation sessions. For both groups ambulation (number of squares entered) decreased over the six sessions $(F 7.3 ;$ df 5,$110 ; P<0.01)$, duration of inactivity increased 
Table 2. Brain weights and DNA-phosphorus content of control $(C)$ and previouslyundernourished $(P U)$ guinea-pigs $\dagger$ at $200 d$ of age

(Mean values with their standard errors; deficits (\%) in parentheses)

\begin{tabular}{|c|c|c|c|c|c|c|c|c|}
\hline & \multicolumn{4}{|c|}{$\mathrm{W}(\mathrm{g})$} & \multicolumn{4}{|c|}{ DNA-P content $(\mu \mathrm{mol})$} \\
\hline & \multicolumn{2}{|c|}{$\mathrm{C}$} & \multicolumn{2}{|c|}{ PU } & \multicolumn{2}{|c|}{$\mathrm{C}$} & \multicolumn{2}{|c|}{ PU } \\
\hline & Mean & SE & Mean & $\mathrm{SE}$ & Mean & SE & Mean & SE \\
\hline Whole brain & $4 \cdot 389$ & 0.032 & $\begin{array}{l}4 \cdot 064 \\
-7 \cdot 4)\end{array}$ & $0.062^{* * *}$ & $20 \cdot 07$ & 0.18 & $\begin{array}{l}18 \cdot 57 \\
\cdot 5)\end{array}$ & $0.30^{* * *}$ \\
\hline Forebrain & $2 \cdot 984$ & 0.022 & $\begin{array}{l}2 \cdot 799 \\
-6 \cdot 2)\end{array}$ & $0.045^{* *}$ & $I I \cdot 05$ & 0.10 & $.10 \cdot 53$ & $0.21 *$ \\
\hline Cerebellum & 0.601 & 0.010 & $\begin{array}{l}0.547 \\
-9.0)\end{array}$ & $0.010^{* *}$ & $5 \cdot 65$ & 0.14 & $.8)^{5 \cdot 15}$ & $0.12^{*}$ \\
\hline Brain stem & 0.806 & 0.013 & $\begin{array}{l}0.719 \\
10.8)^{-}\end{array}$ & $0.013^{* * *}$ & $3 \cdot 36$ & 0.08 & $4 \cdot 3)^{2 \cdot 88}$ & $0.05^{* * *}$ \\
\hline
\end{tabular}

Table 3. Social interactions between mixed pairs of control $(C)$ and previouslyundernourished $(P U)$ guinea-pigs*

(Median values with ranges in parentheses)

Frequency of occurrence (sum of interactions with two partners)

\section{Measure $\dagger$}

Threat

Chase

Bite

Allogroom

Sniff

Mount

Nose

Evade

Flee

Crouch

Ambulation

Initial contact

$\mathrm{C}$
$8(2-2 \mathrm{I})$
$0(0-4)$
$6.5(0-33)$
$9.5(\mathrm{I}-\mathrm{I} 4)$
$8(3-\mathrm{I})$
$0(0-13)$
$15.5(4-40)$
$16.5(3-42)$
$3.5(\mathrm{I}-12)$
$3(1-8)$
$112(35-177)$
$0.5(0-2)$

PU

I I $(3-23)$
$2(0-8)$
$6(I-I)$
IO (2-I6)
$8(I-28)$
$0(0-2)$
$26(8-42)$
I $2(5-3 I)$
$0(0-8)$
$2(0-4)$
I I $4(27-238)$
I $(0-2)$

Statistical significance of differences between treatment groups (two-tailed)

$P<$
$P<0.05$
NS
NS
NS
NS
NS
NS
$P<0.02$
NS
NS
NS

NS, Not significant.

* For details of treatments, see p. 544 .

+ For definitions, see pp. 544-545.

$(F 5.9 ; \mathrm{df} 4,88 ; P<0.01)$ and defaecation increased $\left(F_{3.2} ; \mathrm{df} 5\right.$, I Io; $\left.P<0.05\right)$. Duration of inactivity was recorded on sessions $2-6$ only.

In tests I and 2, when guinea-pigs of unlike-treatment groups were paired, PU animals chased $\mathrm{C}$ animals more than $\mathrm{C}$ chased PU $(P<0.05)$ and, as might therefore have been predicted, $\mathrm{C}$ animals fled from PU animals more than PU from $\mathrm{C}(P<0.05)$. There were no other significant differences in behaviour (Table 3).

In tests 3 and 4 , where pairs of animals of similar nutritional history confronted each other, PU guinea-pigs threatened and nosed each other more than $\mathrm{C}$ guinea-pigs. Their latency to first interaction was also shorter (Table 4).

There are some differences between the comparisons made in the first and second two tests. Thus, in tests 1 and 2 it was not possible to compare $\mathrm{C}$ and PU guinea-pigs for 
Table 4. Social interactions between like-treatment pairs of control $(C)$ and previouslyundernourished $(P U)$ guinea-pigs*

(Median values with ranges in parentheses)

Frequency of occurrence (sum of interactions with two partners)

\section{Measure†}

Threat

Chase

Bite

Allogroom

Sniff

Mount

Nose

Fight

Evade

Flee

Crouch

Ambulation

Latency to interact(s)

$\mathrm{C}$
$8.5(1-18)$
$0(0-10)$
$5.5(1-16)$
$5.5(\mathrm{I}-15)$
$14.5(\mathrm{I}-27)$
$0(0-5)$
$17(2-35)$
$0(0-3)$
$19.5(2-36)$
$1.5(0-8)$
$3(1-5)$
$99(63-195)$
$15(10-322)$

$5(10-322)$

NS, Not significant.

* For details of treatments, see p. 544 .

$\dagger$ For definitions, see pp. 544-545.
Statistical significance of differences between treatment groups (two-tailed)

$P<0.05$
NS
NS
NS
NS
NS
$P<0.04$
NS
NS
NS
NS
NS
$P<0.05$

Table 5. Frequency of responses and response thresholds $(V)$ for control $(C)$ and previously-undernourished (PU) guinea-pigs*

(Median values with ranges in parentheses)

\section{$\mathrm{C}$ \\ PU}

Frequency of responses $\dagger$ Response threshold $\ddagger(V)$

$$
\begin{aligned}
& 24.5(9-39) \\
& 85(60-130)
\end{aligned}
$$

* For details of treatments, see p. 544.

† Total no. of shock presentations, of a total of fifty-four, to which any response was made.

$\ddagger$ The lowest voltage to which guinea-pigs made any response on at least three of the six series of shocks.

activities which required equal participation by both animals, such as fight. It was also not meaningful to compare latency to interact. In tests nos. 3 and 4 , in which guinea-pigs met other animals of like-treatment group these comparisons were possible, but it was not meaningful to record which animal was the initiator.

\section{Shock thresholds}

Expt 1 . It was relatively easy to score accurately for all responses measured and no animal was scored as having responded to the $\mathrm{O} V$ level of stimulation in any series. However, it was difficult to detect a threshold for any of the of the responses recorded: a flinch, move, jump, vocalize, quiver or even a generalized 'response' threshold. There did not seem to be a level of shock above which a guinea-pig consistently responded on any one series or succession of series.

The threshold for any response was therefore arbitrarily defined as the shock level at and above which the response occurred on at least three of the six series. There were no significant differences in response, jump, move, flinch, vocalize or quiver threshold or in the total frequency of any of these measures between $\mathrm{C}$ and PU guinea-pigs (Table 5). All results were analysed using the Mann-Whitney $U$ test. 


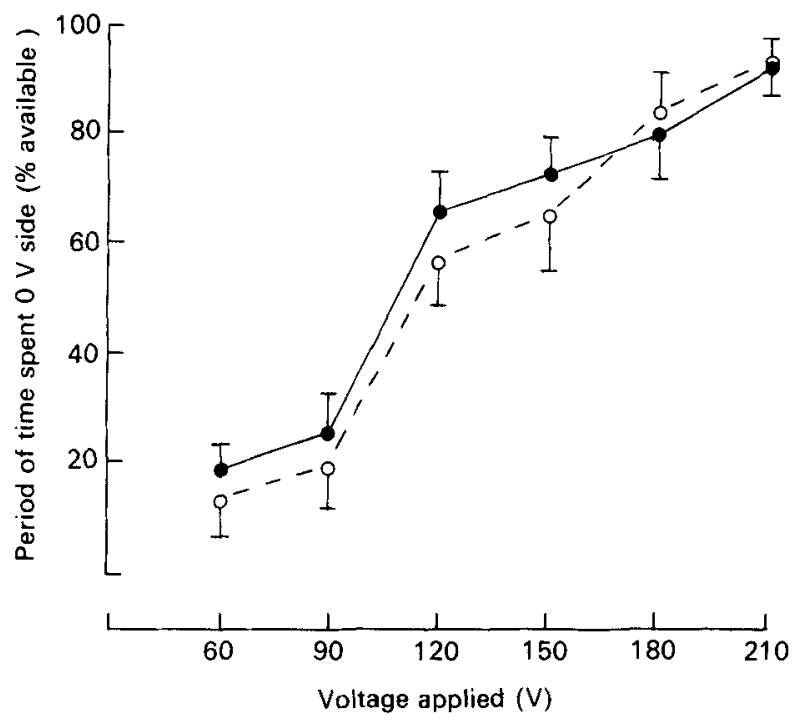

Fig. I. Mean period of time spent (\% available) on the 'no shock' (o V) side of the test apparatus by control $(-)$ and previously-undernourished $(--)$ guinea-pigs. The standard errors are represented by vertical bars. For details of treatments, see p. 544 .

Expt 2. The guinea-pigs moved about very little in the box, except for infrequent short bouts, usually of crossing from side to side. Once again it was difficult to measure a threshold, as very often an animal would cross to the other side of the box on all three presentations of a certain level of shock yet remain immobile at levels of greater intensity.

The total period of time an animal spent on the $\mathrm{V}$ side of the box was measured for each shock level and the level at and above which it spent more than $60 \%$ of the available period of time on this side was defined as the threshold. There was no difference in aversion threshold between $\mathrm{C}$ and PU guinea-pigs (mean \pm SE: C $128 \cdot 0 \pm 12 \cdot 7 \mathrm{~V}, \mathrm{PU} 135.5 \pm 9 \cdot \mathrm{I} \mathrm{V}$ ), nor was there any difference in the period of time spent on the $O \mathrm{~V}$ side at any level of shock (Fig. I). There was also no difference in the mean number of crossings to the 'safe' side or the initial latency to cross at any level of shock.

\section{DIS CUSSION}

The 'catch-up' in body-weight shown here by PU guinea-pigs is contrary to results reported by Chase, Dabiere, Welch \& O'Brien (1971) and Hinz, Thiele \& Dörner (I976) for animals growth-retarded to a similar extent prenatally. Their adult PU animals were significantly lighter than $\mathrm{C}$ animals with a greater absolute deficit in body-weight in adulthood than at birth, immediately after undernutrition. This discrepancy is difficult to explain by any differences in methodology. Different strains of guinea-pigs were used in each instance and this may be a contributory factor. Although both Chase et al. (1971) and Hinz et al. (1976) only used litters of two or three animals, litter size was taken into account statistically in the present study and there was no significant difference between groups in litter size. Rats undernourished during a comparable period of brain growth (throughout the suckling period) show progressively increasing body-weight deficits during nutritional rehabilitation compared with their well-nourished controls (e.g. Widdowson \& McCance, 1963), in a similar manner to the PU guinea-pigs of Chase et al. (I97I) and Hinz et al. (1976). It is possible that in the present study the 'catch-up' may not have been in skeletal or muscle 
growth, but the result of a greater deposition of fat by PU guinea-pigs. Unfortunately, no other measurements of growth were recorded.

The significant deficit in adult brain weight and DNA-P content, however, demonstrates that the guinea-pig brain is vulnerable to prenatal growth restriction, as predicted. The weight deficit is of the same order of magnitude as that reported by Chase et al. (I97I) for guinea-pigs and that found in rats undernourished during the suckling period (Smart, Dobbing, Adlard, Lynch \& Sands, 1973). However, the comparative magnitudes of the regional brain-weight deficits differ from the results of rat studies, in that here the brain stem seems to be the region most affected, whereas in rats the cerebellum is found to be especially vulnerable (Dobbing \& Smart, 1973). Comparison of the present results with those of Chase et al. (1971) is difficult because they do not quote separate values for the brain stem but include it as part of the cerebrum. The selective effects of early undernutrition on the cerebellum in rats has been hypothesized to be due to its relatively faster rate of growth at the time of undernutrition (Dobbing, 1968). This is also a feature of brain growth in guinea-pigs. Between day $4 \mathrm{I}$ of gestation and birth the cerebral hemispheres treble in weight and the brain stem doubles whereas cerebellar weight increases sevenfold and should therefore be most vulnerable to growth restriction (Edwards, Wanner \& Mulley, 1976). However, the cerebellum also continues this greater relative growth rate into postnatal life and may therefore have some capacity for 'catch-up' after birth. One factor which may contribute to their different response to early undernutrition is that the guinea-pig cerebellum is smaller and its brain stem larger than that of the rat in relation to whole brain weight. Interestingly, growth retardation by hyperthermia during the brain growth-spurt (on days 40-44) also results in a deficit in brain weight and affects mainly the brain stem (Edwards, Lyle, Jonson \& Penny, 1974).

The differences in social behaviour between $\mathrm{C}$ and $\mathrm{PU}$ guinea-pigs are all in the direction of greater aggression by $\mathrm{PU}$ animals, with differences in frequency and intensity of performance of behaviours, not of kind. Pairs of PU guinea-pigs began to interact sooner than pairs of $\mathrm{C}$ animals and threatened and nosed each other more often. In mixed pairs PU animals chased $\mathrm{C}$ animals more than this occurred in the opposite direction. These differences are similar to those found in PU rats (Whatson et al. 1974) and also DBA/2J mice, though not in other strains of mice tested (Randt, Blizard \& Friedman, 1975; Smart \& Whatson, 1977). It would therefore appear to be a finding of some generality in laboratory rodents that the development of social behaviour is susceptible to alteration by undernutrition early in life.

The results in the shock-threshold experiments are contrary to the evidence for rats in similar experiments. PU rats show both lower response and aversion thresholds than $\mathrm{C}$ rats, (Smart et al. 1975; Lynch, 1976). However, it was felt that these tests were not very successful measures of reactivity in guinea-pigs due to the lack of consistency in responding, both within and between series of shocks. This may perhaps have been due to conflicting tendencies to 'freeze' or 'flee', which are said to be the principal behavioural responses of the guinea-pig to danger (King, 1956). Alternative and perhaps better methods of measuring responsiveness would be either to include a measure of freezing behaviour, or to measure an involuntary response which changes while the guinea-pig is immobile, such as heart rate or respiration rate (Gerall \& Berg, 1964).

Thus the findings of the present experiments demonstrate that there are some species differences in the physical and behavioural response of animals to undernutrition during the brain growth-spurt. Common to both rat and guinea-pig, however, are lasting deficits in brain growth and distortions of its structure, accompanied by higher levels of social responsiveness and sometimes aggression. 
The authors thank the Medical Research Council for supporting this research and the National Fund for Research into Crippling Diseases for additional financial assistance.

\section{REFERENCES}

Campbell, B. A. (1967). In Early Behaviour, p. 43 [H. W. Stevenson, E. H. Hess and H. L. Rheingold, editors]. New York: John Wiley \& Sons Inc.

Chase, H. P., Dabiere, C. S., Welch, N. N. \& O'Brien, D. (197I). Paediatrics, Springfield 47, 49 I.

Dobbing, J. (1968). In Applied Neurochemistry, p. 287 [A. N. Davison and J. Dobbing, editors]. Oxford: Blackwell.

Dobbing, J. \& Sands, J. (1970). Brain Res. 17, I15.

Dobbing, J. \& Smart, J. L. (1973). In Ethology and Development Clinics. Developmental Medicine, no. 47, p. 16 [S. A. Barnett, editor]. London: Spastics Society and Heinemann.

Edwards, M. J., Lyle, J. G., Jonson, K. M. \& Penny, R. H. C. (I974). Devl. Psychobiol. 7, 579.

Edwards, M. J., Wanner, N. A. \& Mulley, R. C. (1976). Neuropathol. appl. Neurobiol. 2, 439.

Elvidge, H. (1972). J. Inst. anim. Tech. 23, 11 I.

Gerall, A. A. \& Berg, W. S. (1964). Psychol. Rep. 15, 3 II.

Hinz, G., Thiele, D. \& Dörner, G. (I976). Acta biol. med. germ. 35, 1525.

King, J. A. (1956). Ecology 37, 22 I.

Lynch, A. (1976). Physiol. Behav. 16, 27.

Randt, C. T., Blizard, D. A. \& Friedman, E. (1975). Devl. Psychobiol. 8, 275.

Short, D. J. \& Gammage, L. (1959). J. anim. Tech. Ass. 9, 62.

Smart, J. L. (1977). In Genetics, Environment and Intelligence, p. 125. [A. Oliverio, editor]. Elsevier: NorthHolland Biomedical Press.

Smart, J. L., Dobbing, J., Adlard, B. P. F., Lynch, A. \& Sands, J. (1973). J. Nutr. 103, I327.

Smart, J. L. \& Whatson, T. S. (1977). Aggressive Behav. 3, 27 I.

Smart, J. L., Whatson, T. S. \& Dobbing, J. (1975). Br. J. Nutr. 34, 511 .

Tikal, K., Benešová, O. \& Fran̆ková, S. (1976). Psychopharmacologia, 46, 325.

Whatson, 'T. S., Smart, J. L. \& Dobbing, J. (I974). Br. J. Nutr. 32, 413.

Widdowson, E. M. \& McCance, R. A. (1963). Proc. R. Soc. B 158, 329.

Winer, B. J. (1971). Statistical Principles in Experimental Design. New York: McGraw-Hill.

Zamenhof, S., Bursztyn, H., Rich, K. \& Zamenhof, P. J. (1964). J. Neurochem. II, 505. 